\title{
Gênero Psidium: Aspectos Botânicos, Composição Química e Potencial Farmacológico
}

\author{
Emanuelle R. B. Durães, Joelma A. M. de Paula \& Plínio L. F. Naves
}

A família Myrtaceae é considerada uma das maiores famílias botânicas e o gênero Psidium está entre os de maior interesse econômico. Este trabalho tem como objetivo revisar aspectos botânicos, químicos e farmacológicos sobre o gênero Psidium. Os dados foram obtidos de artigos indexados nas bases Periódicos Capes, NCBI, Bireme e SciELO. Suas espécies podem ter folhas simples e opostas, flores solitárias, e frutos com muitas sementes. Dentre as principais propriedades farmacológicas, destacam-se as anti-inflamatórias, antimicrobianas e antioxidantes. As espécies conhecidas de maior importância econômica são: P. guajava, $P$. cattleianum e P. guineense que, por esse motivo, são as mais estudadas.

Palavras-chave: Psidium; composição química e atividades farmacológicas.

The Myrtaceae family is considered one of the largest botanical families and Psidium genus is among the highest economic interest. This work has as objective to review aspects botanical, chemical and pharmacological about Psidium genus. The data were obtained from articles indexed in databases Periodicals Capes, NCBI, Bireme and SciELO. Its species may have simple and opposite leaves, solitary flowers, and fruit with many seeds. The main pharmacological properties there are the anti-inflammatory, antimicrobial and antioxidant. The species among the most economically important are: P. guajava, P. cattleianum and P. guineense for this reason it is the most studied.

Keywords: Psidium; chemical composition and pharmacological activities. 


\section{Introdução}

As plantas medicinais têm sido utilizadas na prevenção e cura de doenças há muitos anos. A descoberta de novos fármacos, a partir de produtos naturais, oriundos de plantas, tem papel relevante no arsenal de medicamentos utilizados no tratamento de várias doenças como, por exemplo, o câncer (KAUR et al., 2011) ${ }^{1}$.

No Brasil, estão presentes os biomas mais ricos em diversidade vegetal do planeta, com mais de 55.000 espécies distribuídas nos seus principais biomas, incluindo um de grande diversidade, o Cerrado. No entanto, apesar desse grande potencial brasileiro, o número de espécies nativas utilizadas para produção de frutos e seus derivados ainda é limitado. Dificuldades com a domesticação, incluindo a propagação e adaptação para cultivo comercial, a natureza altamente perecível do fruto, e a falta de informação quanto a suas características físico-químicas e biológicas têm sido apontados como fatores limitantes que impedem a ampla utilização e consumo de frutas potencialmente relevantes (MEDINA et al., 2011)2.

A família Myrtaceae é considerada mundialmente uma das maiores famílias botânicas e, de acordo com Franzon et al. (2009), ela agrupa mais de 3.600 espécies em cerca de 140 gêneros, distribuídos em todo o mundo. $\mathrm{Na}$ flora brasileira, representa umas das maiores famílias, a qual engloba 23 gêneros e aproximadamente 1000 espécies (SOUZA \& LORENZI, 2005) 4 . Dentre todos os gêneros dessa família que englobam frutíferas, atualmente, quatro têm importância econômica: Eugenia, Acca, Myrciaria e Psidium. Esse último, portanto, ocorre em áreas sob condições de estresse abióticos constantes, incluindo água e temperaturas extremas (COELHO et al., $2004)^{5}$.

Essas plantas estão adaptadas a condições de estresse abiótico, fato que, dentre outras coisas, requer que seus frutos sejam potencialmente ricos em metabólitos secundários, e consequentemente possuam diversas propriedades funcionais. Espécies ricas em compostos fenólicos, ácido ascórbico e carotenos são geralmente associada com propriedades biológicas importantes, tais como o aumento da proteção contra a oxidação celular, atividade antimicrobiana e anticancerígena (MEDINA et al., 2011) .
A família Myrtaceae representa, portanto, uma fonte potencial em metabólitos secundários, pois muitos de seus representantes possuem frutos altamente apreciados, aplicações medicinais validadas por pesquisas científicas e são grandes produtores de óleos essenciais (SUÁREZ; ULATE; CICCIO, 2000; FERNÁNDEZ et al., 2001; GARCÍA et al., 2004; PAULA et al., 2012) ${ }^{6,8}$.

Essa família apresenta uma enorme distribuição tropical, embora possua dois grandes centros de dispersão, um nas Américas e outro na Austrália (SOUZA; LORENZI, 2005) ${ }^{4}$. Como já citado, um dos gêneros dessa família, que apresenta grande interesse comercial e alta ocorrência no bioma Cerrado, é o Psidium, onde se encontram as goiabeiras (Psidium guajava L.) e os araçazeiros (Psidium spp.), espécies apreciadas por seus frutos e, cujas folhas, ricas em compostos fenólicos e óleos essenciais, são utilizadas na medicina popular para o tratamento de diarreia, dentre outras enfermidades (CAMPOS, 2010) $)^{10}$.

De acordo com sua distribuição nativa, o gênero Psidium é considerado neotropical, o qual ocorre do sul do México até a província de Buenos Aires, na Argentina, incluindo ainda o Oeste das Índias, Ilhas do Caribe, e dois arquipélagos no Pacífico, o de Galápagos e as Ilhas Revillagigedo (FRANZON et al., 2009; VIEIRA et al., 2006) 3 , 11 .

No que diz respeito ao potencial medicinal dos araçás do Cerrado, recente levantamento etnobotânico aponta a utilização das folhas e dos brotos por moradores de áreas urbanas, de assentamentos e de comunidades quilombolas do Cerrado goiano para o tratamento de disenterias (CAMPOS, 2010) ${ }^{10}$.

Dados da literatura científica reforçam o potencial farmacológico de espécies de araçás, pois são registradas importantes atividades biológicas atribuídas aos frutos e folhas destas espécies, tais como: antioxidante, antimicrobiana, antiproliferativa sobre células tumorais humanas e aumento do sono induzido por cetamina em camundongos (CORRÊA et al., 2011; FAUTH et al., 2002; MEDINA et al., 2011; OLIVEIRA et al., 2012; PATEL, 2012; VOSS-RECH et al., 2011) 2, 12, 13, 14, 16 .

Tendo em vista a importância da etnobotânica de espécies do gênero Psidium, em especial ao que se refere à etnofarmacologia, o presente trabalho teve como objetivo revisar os principais aspectos botânicos, 
químicos e farmacológicos descritos na literatura. Esses dados poderão subsidiar estudos multidisciplinares futuros, envolvendo espécies desse gênero e contribuirão para análise crítica da utilização pela população, com vistas à preservação dos valores culturais, à preservação das espécies vegetais nos respectivos biomas e à promoção do uso racional de espécies vegetais como recurso terapêutico.

\section{Fontes dos Dados}

Para a realização desse trabalho, buscaram-se artigos originais e revisões indexados nas bases Periódicos Capes, NCBI, Bireme e Scielo. Utilizaram-se as palavraschave Myrtaceae e Psidium. Buscaram-se ainda dados relevantes contidos em livros nacionais e internacionais que tratam de assuntos, tais como botânica, química de produtos naturais, fitoterapia e farmacognosia. Não houve restrição no que se refere ao ano de publicação.

\section{ASPECTOS BOTÂNICOS E COMPOSIÇÃO QUÍMICA DO GÊNERO PSIDIUM}

Esse gênero se caracteriza por apresentar em suas espécies: folhas simples e opostas com típica venação broquidódroma e flores solitárias, axilares ou em pequenos racemos, dicásio ou botrioides. Além disso, as flores são pentâmeras e os botões maduros variam de 4-15mm; o cálice possui morfologia variável, oscilando de cupuliforme até caliptrato e raramente apendiculado. As pétalas são livres e alternadas de cor branca ou creme, com vários estames, variando de 60 até 320, arranjados de 3 a 12 verticilos, o ovário é ínfero com 2 a 5 lóculos, com placentação intrusiva. Os frutos normalmente se desenvolvem com muitas sementes, as quais apresentam testa óssea e embrião coclear com cotilédones apicais (FRANZON et al., 2009; SOARES-SILVA, PROENÇA, $2008)^{3,17}$.

Dentre as 100 espécies desse gênero, merecem destaque os araçazeiros pela característica de seus frutos com sabor exótico e elevado teor de vitamina $\mathrm{C}$. Recentemente, em pesquisa realizada na Universidade de Brasília, foi encontrada em uma das espécies de araçás (Psidium myrsinites DC.), uma substância usada na composição de perfumes, o linalol (FRANZON et al., 2009; PRESTES et al., 2011) $)^{3,18}$.

P. myrsinites, popularmente conhecido como araçazeiro, é uma fruteira nativa do Brasil, podendo ser encontrada desde o Estado do Rio Grande do Sul, passando por Minas Gerais, até a região Amazônica. Atualmente, essa espécie está sendo muito estudada, principalmente, pelas excelentes características de seus frutos, que podem apresentar entre quatro a sete vezes mais vitamina $\mathrm{C}$ que as frutas cítricas. Essas características dos frutos, juntamente com a vantagem de sua precocidade de produção, começando a produzir, já no segundo ano após o plantio da muda, e sua regular resistência às doenças e pragas, tornam o araçazeiro uma nova e promissora opção de cultivo, especialmente, para os pequenos produtores rurais (WILLE et al., 2004) ${ }^{19}$.

A presença do linalol no óleo essencial de $P$. myrsinites é relevante, visto a importância desse composto como fixador para a indústria de perfumes e a possibilidade de se ter novas fontes desse produto pode vir a contribuir com o setor de óleos essenciais. O óleo essencial analisado por cromatografia gasosa acoplada à espectrometria de massas (GC/MS) demonstrou a presença principalmente de sesquiterpenos como o óxido de cariofileno, $\beta$-cariofileno, $\beta$-guaiano, humuleno e viridiflorol, além de monoterpenos como a mirceno. Os presentes compostos, portanto, emprestam a essa espécie um grande potencial para ser usado em diversos setores que necessitem de aromas como na indústria de perfumes, devido à presença de compostos aromatizantes em sua composição (CASTELO et al., 2010, CASTELO et al., 2012) ${ }^{20}$.

No trabalho de Medina et al (2011) ${ }^{21}$, ele se concentrou em determinar a composição química e o potencial funcional de acessos vermelho e amarelo de Psidium cattleianum Sabine (araçá ou goiaba morango) cultivadas no Sul do Brasil. No seu levantamento, os frutos de $P$. cattleianum apresentaram um teor de fenólicos totais maior do que o morango (Fragaria ananassa Duch.) e a uva (Vitis vinifera L.), e na mesma faixa da pitanga (Eugenia uniflora L.) e da amora-preta (Rubus L.). Em comparação com a pitangueira ou amora, araçá é mais ácida e tem menor teor de ácido L-ascórbico, caroteno e antocianinas. Já no estudo de Moon et al (2011) ${ }^{32}$ os principais constituintes fitoquímicos, identificados na fração clorofórmica do extrato das folhas dessa espécie foram: ácido ferúlico, genisteína, 3',4',5' trimetoxi flavona, floridizina e ácido oleanólico. 
O estudo demonstrou que as antocianinas totais encontradas em $P$. cattleianum vermelho foram relativamente baixas em relação à maioria das frutas vermelhas como a pitangueira. Epicatequina, seguido de ácido gálico, foram os principais compostos fenólicos presentes em todos os genótipos investigados para ambos P. cattleianum amarelo e vermelho.

Os frutos de $P$. cattleianum não são utilizados industrialmente, mas é comumente usado em suco ou geleia, devido a sua polpa suculenta e um sabor agradável. Eles medem entre 1,5 e 2,5 cm, de diâmetro, e têm uma grande quantidade de sementes, das quais se extrai o ácido linoleico. Este óleo é de grande interesse porque pode ser utilizado tanto para consumo humano quanto para fins industriais, como na produção de cosméticos e vernizes (KOBELNIC et al., 2012) 23 $^{23}$.

No entanto, a pesquisa de Chalannavar et al. (2012) mostra que o Psidium cattleianum var. lucidum, espécie encontrada no Sul da África, apresentou, dentre vários outros compostos no seu óleo essencial, óxido de cariofileno, um sesquiterpeno oxigenado, o qual é considerado componente importante na maioria das espécies de Psidium. Este composto é considerado ainda um dos principais constituintes do óleo essencial, a partir de folhas de goiabeira de vários países como China, Cuba, Nigéria, além de ser encontrada em outras espécies levantadas pelo autor: P. myrsinites, P. salutare, $P$. striatulum e P. guajava.

No estudo de Yanéz et al. (2002) com a espécie Psidium caudatum McVaugh também foram encontrados por análise de CG, monoterpenos como componente principal da amostra de óleo essencial.

De acordo com o trabalho de Wille et al. (2004), o Psidium acutangulum D.C., araçá-pera, ou goiaba selvagem, como é conhecido na região do Paraná, está sendo cultivado pela Estação Experimental do IAPAR, Instituto Agronômico do Paraná, localizada na cidade de Morretes visando ao aproveitamento comercial dos frutos no litoral paranaense e possibilitando novas oportunidades de sustento para os habitantes da região. Seu estudo baseou-se no desenvolvimento de formulações que facilitassem o processamento desse fruto.

Por ser a espécie mais estudada desse gênero, existem vários trabalhos relatando a composição química e atividade biológica de Psidium Guajava L., popularmente conhecida como goiabeira. Essa espécie apresenta grande quantidade de compostos fenólicos, carotenoides e triterpenoides (GUTIERREZ et al., $2008)^{26}$, principalmente, da série ursano e oleanano, tais como: uvaol, Ilelatifol D, além dos ácidos oleanólico, ursólico e cratególico, 2- $\alpha$-hidroxiursólico, guavanóico, ácido guavacumárico, entre outros. A espécie $P$. guajava apresenta, também, altas concentrações de flavonoides; entre eles, uma série de derivados glicosídicos de quercetina e alguns de miricetina, morina, além das agliconas leucocianidina, canferol e catequina (MORESCO, 2014) ${ }^{27}$.

Recentemente, foi isolado um novo composto dessa espécie, P. guajava, o (+)-Guajadial B, um meroterpenoide isolado a partir das folhas dessa espécie colhidas no Vietnã (GAO, 2012) . $^{28}$.

Ao analisar a fração acetato de etila da goiaba em Costa Rica (Psidium friedrichsthalianum), identificaramse compostos com significativas atividades biológicas como 1-O-trans-cinamoil-BD-glucopiranose, ácido elágico, miricetina, quercitrina, e quercetina, além de Citrato de 1,5-dimetil, o aldeído sinápico 4-O- $\beta$-Dglucopiranose, 3,3',4-tri-O-ácido metilelágico-4'-O-Dglucopiranósido, e 1,3-O-diferuloilglicerol (FLORES et al., 2013) $)^{32}$.

Por um processo de hidrodestilação, quatro espécies de Psidium tiveram seus óleos extraídos e identificados em GC/MS, Psidium acutangulum, P. striatulum Mart. Ex DC, P. guineense Sw e P. guajava. Dentre tantos constituintes identificados, os principais foram: no óleo de P. acutangulum, $\alpha$-pineno (14,8\%), 1,8-cineol (12,9\%) e $\beta$-pineno (10,1\%); no óleo de P. striatulum, $\beta$-cariofileno (28,6\%), $\alpha$-selineno $(7,7 \%)$, óxido de cariofileno $(7,6 \%)$, $\beta$-selineno $(7,4 \%)$ e selin-11-en- $4 \alpha$-ol $(6,0 \%)$; no óleo de $P$. guineense foram $\beta$-bisabolol (17,4\%), limoneno $(6,8 \%)$ e epi- $\alpha$-bisabolol $(6,7 \%)$ e no óleo de goiaba foram encontrados $\alpha$-pineno (23,9\%), 1,8-cineol $(21,4 \%)$ e $\beta$-bisabolol $(9,2 \%)$ (SILVA et al., 2003) ${ }^{30}$.

\section{Potencial Farmacológico}

De acordo com Franzon et al (2009) ${ }^{11}$, dentre as espécies conhecidas de Psidium, a de maior expressão é a $P$. guajava, a goiabeira, provavelmente pelo aproveitamento de seus frutos na fabricação de doces, geleias, sucos, consumo in natura e pela utilização 
de suas folhas no combate a problemas de natureza gastrointestinal, como, por exemplo, para o tratamento de disenteria na infância e inflamações de boca e de garganta. Já, com menor expressão, foi destaque a $P$. cattleyanum e $P$. guineense, uma vez que as duas não apresentam exploração econômica em plantios comerciais (PRESTES et al., 2011) ${ }^{18}$.

Gonçalves et al. $(2008)^{14}$ demonstrou, através da técnica de difusão de disco ,que o óleo essencial e o extrato metanólico de P. guajava apresentam importante atividade antimicrobiana frente a cepas de Staphylococcus aureus e Salmonella spp, o que faz dessa espécie uma importante fonte de antimicrobiano.

Essa espécie foi ainda avaliada quanto a sua atividade antioxidante. Três cultivares de P. guajava: branco, rosa e vermelho, após avaliação, sugeriram que os extratos dos frutos de $P$. guajava são potentes varredores de radicais livres e podem ser utilizados como uma boa fonte de antioxidantes naturais para alimentos, produtos farmacêuticos, médicos e utilizações comerciais. No entanto, a atividade antioxidante e a composição química variam significativamente, de acordo com a coloração da polpa (FLORES et al., 2015) (2) $^{32}$

Em uma outra pesquisa, porém, com a síntese de nanopartículas de prata usando extrato das folhas de $P$. guajava, essa espécie apresentou atividade antimicrobiana contra bactérias Gram-positivas, bactérias patogênicas humanas Gram-negativas, e fungos. As nanopartículas mostraram ainda habilidade proeminente para inibir os biofilmes formados por Staphylococcus aureus, Escherichia coli e Candida albicans o que sugere promissoras aplicações de constituintes dessa espécie em materiais de revestimentos anti-microbianos, especialmente em dispositivos cirúrgicos e implantes sintéticos (GUPTA et al., 2014) (33. $^{33}$

Com o intuito de avaliar a toxicidade do extrato etanólico de $P$. guajava e $P$. guineense, Sánchez \& Neira (2005) realizaram testes com Artemia salina com a fração acetato de etila obtida do extrato etanólico dos frutos dessas duas espécies de Psidium, e verificaram concentrações letais moderadamente tóxicas, podendo assim ser um indicador para se orientar investigações futuras em busca de novos bioativos.

O óxido de cariofileno, identificado em várias espécies de Psidium, tem sido associado ainda à atividade antimicrobiana, analgésica, anti-inflamatória e antifúngica contra dermatófitos, e ainda atividade anticárie em ratos, além de ser bastante conhecido como um conservante em alimentos, medicamentos e cosméticos. Como os óleos essenciais são amplamente utilizados como ingrediente de sabor em uma ampla variedade de alimentos, bebidas e confeitaria, verficou-se ainda que a presença de óxido de cariofileno dominante em óleos essenciais os tornam potenciais conservantes naturais na indústria de alimentos (CHALANNAVAR et al., 2012) $)^{24}$.

De acordo com os estudos de Moon et al (2011), a fração clorofórmica do extrato das folhas de $P$. cattleianum Sabine, ao ser avaliada com várias linhagens celulares do cancro, revelou um potencial significativo para o tratamento do câncer gástrico humano, uma vez que induziram positivamente a apoptose nas células cancerígenas testadas. P. cattleianum vermelho e amarelo foram testados por Medina et al. (2011) devido a sua possível atividade antioxidante, antimicrobiana e efeito antiproliferativo contra células humanas cancerígenas atribuídas à presença de compostos fenólicos.

A presença de epicatequina em alimentos, como no P. cattleianum pode contribuir para a redução dos riscos de desenvolver doenças cardiovasculares, devido ao seu papel na vasodilatação, diminuindo a pressão sanguínea e como um componente na atividade antioxidante, além do seu potencial antimicrobiano (KATALINIC et al., 2010; SCHROETER et al., 2005) $)^{35,36}$. Além disso, os polifenóis podem desempenhar um papel importante na prevenção do câncer por mecanismos genéticos, principalmente, por metilação do DNA, impedindo a modificação das histonas e regulação da expressão mRNA (LINK et al., $2010)^{37}$.

Este estudo demonstrou, portanto, atividade antioxidante, antimicrobiana e antiproliferativa dos extratos dos frutos de P. cattleianum Sabine vermelho e amarelo. Extratos acetônicos mostraram maior atividade antioxidante, o que foi correlacionado a níveis elevados de compostos fenólicos. Os extratos aquosos e acetona demonstraram eficiência em ensaios antioxidante frente ao Saccharomyces cerevisiae, fornecendo proteção contra o peróxido de hidrogênio e levando à célula taxas de sobrevivência acima de $80 \%$. Extratos de $P$. cattleianum também exibiram atividade antimicrobiana 
contra bactérias patogênicas Salmonella enteritidis. Esses resultados revelam $P$. cattleianum como fonte de antioxidantes naturais, efeito antimicrobiano e antiproliferativo com aplicação tanto em alimentos como na indústria farmacêutica (MEDINA et al., 2011)2 .

Na medicina popular, a espécie $P$. myrsinites é utilizada para cicatrização, devido a suas propriedades adstringentes e contra diarreia. No entanto, existem poucos estudos que validem suas atividades farmacológicas e elucidem a composição química dessa espécie (FRANZON et al., 2009) ${ }^{3}$. No estudo de Pereira (2010), a espécie P. myrsinites é relatada com três possíveis quimiotipos, ou seja, a mesma espécie apresentando óleos essenciais com variações qualitativas e quantitativas, indicando que essas espécies podem apresentar atividades distintas, bem como diferenças morfológicas. Os resultados obtidos no referido estudo indicaram que os óleos essenciais das espécies do gênero Psidium apresentam atividade antimicrobiana, principalmente contra as linhagens Gram-positivas.

Os efeitos terapêuticos potenciais de uma espécie de goiaba da Costa Rica (Psidium friedrichsthalianum) sobre doença pulmonar obstrutiva crônica (DPOC) também foi avaliado. Em comparação com as frações hexano, clorofórmio e n-butanol, além do próprio extrato bruto dos frutos dessa espécie, a fração acetato de etila apresentou-se com maior atividade antioxidante e melhor efeito anti-inflamatório contra interleucina-8 (IL-8) e inibição de metaloproteinase de matriz-1 (MMP-1). Sendo assim, os constituintes presentes nessa fração, além de apresentarem atividade antioxidante, mostramse como um grande potencial para o tratamento da DPOC, devido a sua capacidade em reduzir a inflamação causada pela exposição a fumaça de cigarro (FLORES et al., 2013) ${ }^{29}$.

Oliveira et al. (2012) ao buscar dados de plantas nativas brasileiras, relatou importantes informações dos potenciais que esses vegetais apresentam à população consumidora. Dentre várias citadas pelo autor, as do gênero Psidium foram $P$. cattleyanum, P. guajava, Psidium guineense $S w$. e Psidium rufum DC (araçás). Estudos identificaram ainda atividades farmacológicas da P. guajava no tratamento de diabetes, uma vez que seu extrato reduziu significativamente os níveis de glicemia e o acúmulo de gordura no fígado (OWEN et al., 2008) ${ }^{39}$.
Além do potencial antioxidante demonstrado pelos araçás (OLIVEIRA et al., 2012) ${ }^{14}$.

Corrêa et al. (2011) demonstraram atividade farmacológica de espécies de Psidium, na qual resultaram em atividade antioxidante. Sendo assim, os autores identificaram compostos presentes na goiabeira (P. guajava) e nos araçás (Psidium ssp.) responsáveis por essa atividade, tais como os compostos fenólicos, além da presença de carotenoides, como o licopeno, $\beta$-caroteno e ácido ascórbico livre.

\section{Conclusão}

As características botânicas macroscópicas descritas neste trabalho, como as referentes à disposição das folhas opostas, são facilmente visíveis presença de flores solitárias, pentâmeras, de cor branca ou creme e frutos repletos de sementes, corroboram a classificação desse gênero dentro da família Myrtaceae.

Estudos científicos respaldaram a maioria dos usos medicinais que pessoas, de diversas partes do mundo, fazem das plantas do gênero Psidium. Além disso, propriedades farmacológicas não referidas pela população foram também observadas em modelos experimentais. Muitas dessas ações foram atribuídas aos componentes majoritários dos óleos essenciais, na maioria, presentes nas folhas. No entanto, outros metabólitos secundários também podem contribuir para essas atividades.

As espécies mais estudadas são a $P$. guajava, P.cattleianum e a P.guineense. A composição química dos óleos essenciais dessas plantas é fundamental para determinar a atividade delas e, como muitas têm componentes em comum, também podem ter ações semelhantes. Por isso, as demais espécies, provavelmente, têm importantes ações farmacológicas que merecem ser investigadas.

\section{Referências}

1. Campos, L.Z.O. Etnobotânica do gênero Psidium L. (Myrtaceae) no Cerrado brasileiro. 2010. 71f. Dissertação (Mestrado em Botânica) - Instituto de Ciências Biológicas, Universidade de Brasília, Brasília, 2010.

2. Castelo, A. V. M.; Del MenezzI, C. H. S.; Resck, I. S. Seasonal Variation in the Yield and the Chemical Composition of Essencial Oils from two Brazilian Native Arbustive Species. Journal of Applied Sciences. v. 12 n. 8, p. 753-760, 2012. 
3. Castelo, A. V. M.; Menezzi, C. H. S.D, Resck, I. S. Rendimento e Análises Espectroscópica (RMN 1H, 13C; IV) da composição química dos óleos essenciais de quatro plantas do cerrado. CERNE, vol $16 \mathrm{n}^{\circ}$ 4, outubro - dezembro, 2010, pp. 573 - 584, Universidade Federal de Lavras.

4. Chalannavar, R. K.; Narayanaswamy, V. K.; Baijnath, H.; Odhav, B. Chemical composition of essential oil of Psidium cattleianum var. lucidum (Myrtaceae). African Journal of Biotechnology. v. 11 n.33, p. 8341-8347, April, 2012.

5. Coelho, S. G.; Hass, A. P. S.; Poser, G. L.; Schapoval, E. E. S.; Elisabetsky, E. Ethnopharmacological studies of antimicrobial remedies in South of Brazil. Journal of Ethnopharmacology, v. 90, p. 135-143, 2004.

6. Corrêa, L.C.; Santos, C.A.F.; Vianello, F.; Lima, G.P.P. Antioxidant contente in guava (Psidium guajava) and araçá (Psidium spp.) germplasm from different Brazilian regions. Plant Genetic Resources: Characterization and Utilization, v. 9, n. 3, p. 384 - 391, 2011.

7. Fauth, S.; Campos, A.R.; Silveira, E.R.; Rao, V.S. Efeitos de óleos essenciais de plantas no tempo de sono induzido por cetamina em camundongos. Revista Brasileira de Farmacognosia, v. 12, supl., p. 112-113, 2002.

8. Fernández, A. Alvarez, A., Garcia, M. D., Saenz, M. T. Antiinflammatory effect of Pimenta racemosa var. ozua and isolation of the triterpene lupeol. Il Fármaco, v.56, p.335-338, 2001.

9. Flores, G., Dastmalchi, K., WU, S., Whalen, K., Dabo, A. J., Reynertson, K. A., Foronjy, R. F. D’Armiento, J. M., Kennelly, E. J. Phenolic-rich extract from the Costa Rican guava (Psidium friedrichsthalianum) pulp with antioxidant and anti-inflammatory activity. Potential for COPD therapy. Food Chemistry. v. 141, p. 889-895, 2013.

10. Flores, G., WU, S., Negrin, A., Kennelly, E. J. Chemical composition and antioxidant activity of seven cultivars of guava (Psidium guajava) fruits. Food Chemistry. v. 170, p. 327-335, 2015.

11. Franzon, R.C.; Campos, L.Z.O.; Proença, C.E.B.; Sousa-Silva, J.C. Araças do gênero Psidium: principais espécies, ocorrência, descrição e usos. Planaltina/DF: Embrapa Cerrados, 2009.

12. Gao, Y., Wang, G., Wei, K., Hai, P., Wang, F., Liu, J. Isolation and Biomimetic Synthesis of (()-Guajadial B, a Novel Meroterpenoid from Psidium guajava. Organic Letters. v. 14, n. 23, p. 59365939, 2012.

13. García, M. D., Fernández, A. Alvarez, A., Saenz, M. T. Antinociceptive and anti-inflammatory effect of the aqueous extract from leaves of Pimenta racemosa var. ozua (Mirtaceae). Journal of Ethnopharmacology. v. 91, p. 69-73, 2004.

14. Gonçalves, F. A.; Andrade, N. M.; Bezerra, J. N. S.; Macrae, A.; Sousa, O. V.; Fonteles-Filho, A. A. Antibacterial activity of GUAVA, Psidium guajava Linnaeus, leaf extracts on diarrhea-causing enteric bacteria isolated from Seabob shrimp, Xiphopenaeus kroyeri (Heller). Rev Inst Med Trop S Paulo. v. 50, n. 1, p. 5-11, 2008.
15. Gupta, K., Hazarica, S. N., Saikia, D., Namsa, N. D., Mandal, M. One step green synthesis and anti-microbial and anti-biofilm properties of Psidium guajava L. leaf extract-mediated silver nanoparticles. Materials Letters. v. 125, p. 67-70, 2014.

16. Gutierrez, R. M., Mitchelll, S., Solis, R. V. Psidium guajava: a review of its traditional uses, phytochemistry and pharmacology. Journal of Ethnopharmacology, v. 117 n.1, p. 1-27, 2008.

17. Katalinic, V., Mozina, S. S., Skroza, D., Generalic, I., Abramovic, H., Milos, M., Ljubenkov, I., Piskernik, S., Pezo, I., Terpinc, P., Boban, M. Polyphenolic profile, antioxidant properties and antimicrobial activity of grape skin extracts of 14 Vitis vinifera varieties grown in Dalmatia (Croatia). Food Chemistry. v. 119, n. 2, p. 715-723, 2010.

18. Kaur, R.; Kapoor, K.; Kaur, H. Plants as a source of anticancer agents. Journal Natural Product and Plant Resourse, v. 1 n. 1, p. 119-124, 2011.

19. Kobelnik, M., Cassimiro, D. L., Dias, D. S., Ribeiro, C. A., Crespi, M. S. Thermal behavior of araça oil (Psidium cattleianum Sabine). J Therm Anal Calorim. V. 108. p. 1281-1286, 2012.

20. Link, A., Balaguer, F., Goel, A. Cancer chemoprevention by dietary polyphenols: Promising role for epigenetics. Biochemical Pharmacology. v. 80. p. 1771 - 1792, 2010.

21. Medina, A.L.; Haas, L.I.R.; Chaves, F.C.; Salvador, M.; Zambiazi, R.C.; Silva, W.P.; Nora, L.; RombaldI, C.V. Araçá (Psidium cattleianum Sabine) fruit extracts with antioxidant and antimicrobial and antiproliferative effect on human cancer cells. Food Chemistry, v. 128, p. 916-922, 2011.

22. Moon, J. Y., Mosaddik, A., Kim, H., Cho, M., Choi, H. K., Kim, Y. S., ChO, S. K. The chloroform fraction of guava (Psidium cattleianum sabine) leaf extract inhibits human gastric cancer cell proliferation via induction of apoptosis. Food Chemistry. v. 125, p. 369-375, 2011.

23. Moresco, H. H. Estudo fitoquímico e biológico de quarto espécies da família Myrtaceae. 2014. 190p. Dissertação (Doutorado) Programa de Pós-Graduação em Química. Universidade Federal de Santa Catarina, Florianópolis.

24. Oliveira, V. B., Yamada, L. T., Fagg, C. W., Brandão, M. G. L. Native foods from Brazilian biodiversity as a source of bioactive compounds. Food Research International. v. 48, p. 170-179, 2012.

25. Owen, P. L., Martineau, L. C., Caves, D., Hsddad, P. S., Matainaho, T. Consumption of guava (Psidium guajava L.) and noni (Morinda citrifolia L.) may protect betel quid-chewing Papua New Guineans against diabetes. Asia Pacific Journal of Clinical Nutrition. v. 17, p. 635-643, 2008.

26. Patel, S. Exotic tropical plant Psidium cattleianum: a review on prospects and threats. Rev. Environ. Sci. Biotechnol., v. 11, p. 243-248, 2012.

27. Paula, J.A.M.; Silva, M.R.R.; Costa, M.P.; Diniz, D.G.A.; SÁ, F.A.S.; Alves, S.F.; Costa, E.A.; Lino, R.C.; Paula, J.R. Phytochemical analysis and antimicrobial, antinociceptive, and ati-inflammatory activities of two chemotypes of 
Pimenta pseudocaryophyllus (Myrtaceae). Evidence-Based Complementary and Alternative Medicine, p. 1-15, 2012.

28. Pereira, C. K. B. Estudo químico e atividades microbiológicas de espécies do gênero Psidium (Myrtaceae). 2010. 120p. Dissertação (Mestrado) - Programa de Pós-Graduação em Bioprospecção Molecular. Universidade Regional de Cariri, Cariri.

29. Prestes, L. S.; Schuch, L. F. D.; Alves, G. H.; Santos, M. A. Z.; Rodrigues, M. R. A.; Meireles, M. C. A.; Evaluación de la actividad bactericida de aceites esenciales de hojas de guayabo, pitango y arazá. Revista Cubana de Plantas Medicinales. v.16, n.4, p. 324-330, 2011.

30. Sánchez, L., Neira, A. Bioensayo general de letalidade en Artemia salina, a las fracciones del extracto etanólico de Psidium guajava L. y Psidium guineense Sw. Cultura Científica. p. 40-45, octubre, 2005.

31. Schroeter, H., Heiss, C., BalzeR, J., Kleinbongard, P., Keen, C. L., Hollenberg, N. K., Sies, H., Kwik-Uribe, C., Schmitz, H., Kelm, M. (-)-Epicatechin mediates beneficial effects of flavanolrich cocoa on vascular function in humans. Proceedings of the National Academy of Sciences of the United States of America. v. 103, n. 4, p. 1024-1029, 2005.

32. Silva, J. D., Luz, A. I. R., Silva, M. H. L., Andrade, E. H. A. Essential oils of the leaves and stems of four Psidium spp. Flavour Fragr. J. v. 18, p. 240-243, 2003.

33. Soares-Silva, L. H., Proença, C. E. B. A new species of Psidium L. (Myrtaceae) from southern Brazil. Botanical Journal of the Linnean Society. v. 158, p. 51-54, 2008.

34. Souza, V. C., Lorenzi, H. Botânica sistemática: guia ilustrado para identificação das famílias de Angiospermas da flora brasileira, baseado em APG II. São Paulo: Ed. Nova Odessa. Instituto Plantarum, 2005. 640 p.

35. Suarez, A.; Ulate, G., Ciccio, J. F. Hypotensive action of an aqueous extract of Pimenta dioica (Myrtaceae) in rats. Rev. biol. Trop. v.48, n.1, p. 53-58, 2000.
36. Vieira, R. F., Costa, T. S. A., Silva, D. B., Ferreira, F. R., Sano, S. M. Frutas Nativas da região Centro-Oeste do Brasil. Brasília: Embrapa recursos genéticos e Biotecnologia, 2006. 320p.

37. Voss-Rech, D.; Klein, C.S.; Techio, V.H.; Scheuermann, G.N.; Rech,G.; Fiorentin, L. Antibacterial activity of vegetal extracts against serovars of Salmonella. Ciência Rural, v. 41, n. 2, p. 314320, 2011.

38. Wille, G. M. F. C.; Macedo, R. E. F.; Masson, M. L.; Stertz, S. C.; Neto, R. C.; Lima, J. M. Desenvolvimento de Tecnologia para a fabricação de doce em massa com araçá-pêra (Psidium acutangulum D. C.) para o pequeno produtor. Ciênc. agrotec. v. 28, n. 6, p. 1360-1366, nov./dez., 2004.

39. Yáñez, X.; Pinzón, M. L.; Solano, F.; Sánchez, L. R. Chemical Composition of the Essential Oil of Psidium caudatum McVaugh. Molecules. v. 7, p. $712-716,2002$.

\section{Emanuelle R. B. Durães*, Joelma A. M. de Paula \& Plínio L. F. Naves}

Universidade Estadual de Goiás, Programa Ciências Aplicadas a Produtos para Saúde, Br 153, Km 98, Campus Henrique Santillo, CEP: 75001-970, Anápolis-Brasil

*E-mail: emanuelle.farma@gmail.com. 